\title{
The role of sediment subduction and buoyancy on subduction dynamics and geometry
}

S. Brizzi ${ }^{1}$, T.W. Becker ${ }^{1}$, C. Faccenna ${ }^{1,2}$, W. Behr ${ }^{3}$, I. van Zelst ${ }^{4}$, L. Dal Zilio ${ }^{5}$, Y. van Dinther ${ }^{6}$

${ }^{1}$ Jackson School of Geosciences, The University of Texas at Austin, Austin, TX, USA. ${ }^{2}$ Laboratory of Experimental Tectonics, University of Roma Tre, Rome, Italy. ${ }^{3}$ Department of Earth Science, ETH Zürich, Zürich, Switzerland. ${ }^{4}$ Institute of Geophysics and Tectonics, School of Earth and Environment, University of Leeds, Leeds, UK. ${ }^{5}$ Seismological Laboratory, California Institute of Technology, Pasadena, CA, USA. ${ }^{6}$ Department of Earth Sciences, Utrecht University, Utrecht, The Netherlands.

This manuscript is a preprint uploaded to EarthArxiv. This preprint has been submitted for publication in Geophysical Research Letters and has not yet been peer-reviewed. We welcome feedback, discussion and comments at any time. Feel free to get in touch with one of the authors. 


\title{
The role of sediment subduction and buoyancy on subduction dynamics and geometry
}

\author{
S. Brizzi ${ }^{1}$, T.W. Becker ${ }^{1}$, C. Faccenna ${ }^{1,2}$, W. Behr ${ }^{3}$, I. van Zelst ${ }^{4}$, L. Dal \\ Zilio $^{5}$, Y. van Dinther ${ }^{6}$ \\ ${ }^{1}$ Jackson School of Geosciences, The University of Texas at Austin, Austin, TX, USA \\ ${ }^{2}$ Laboratory of Experimental Tectonics, University of Roma Tre, Rome, Italy \\ ${ }^{3}$ Department of Earth Science, ETH Zürich, Zürich, Switzerland \\ ${ }^{4}$ Institute of Geophysics and Tectonics, School of Earth and Environment, University of Leeds, Leeds, UK \\ ${ }^{5}$ Seismological Laboratory, California Institute of Technology, Pasadena, CA, USA \\ ${ }^{6}$ Department of Earth Sciences, Utrecht University, Utrecht, The Netherlands
}

\section{Key Points:}

- We conduct 2D thermomechanical models of subduction with variable sediment thickness and density

- Thick sediments can increase resistance along the subduction interface and decrease slab pull leading to a slower subducting plate

- Sediments can act as a lubricant for long-term subduction, but buoyancy and accretionary wedge development are also important. 


\begin{abstract}
Subducted sediments are thought to lubricate the subduction interface and promote faster plate speeds. However, global observations are not clear-cut on the relationship between the amount of sediments and plate motion. Sediments are also thought to influence slab dip, but variations in subduction geometry depend on multiple factors. Here we use 2D thermomechanical models to explore how sediments can influence subduction dynamics and geometry. We find that thick sediments can lead to slower subduction due to an increase of the megathrust shear stress as the accretionary wedge gets wider, and a decrease in slab pull as buoyant sediments are subducted. Our results also show that larger slab buoyancy and megathrust stress due to thick sediments increase the slab bending radius. This offers a new perspective on the role of sediments, suggesting that sediment buoyancy and wedge geometry also play an important role on large-scale subduction dynamics.
\end{abstract}

\title{
Plain Language Summary
}

At subduction zones, an oceanic plate dives into the mantle below another plate. The downgoing plate is usually covered by sediments. These sediments can be carried down to depth along the interface and/or scraped off the top of the downgoing plate and appended to the edge of the upper plate, forming an accretionary wedge. Sediments subducted to depth act as a lubricant, influencing the shear resistance of the interface, and in turn, downgoing plate speed. However, natural data show that slow subduction can be associated with thick sediments. Sediments are also thought to affect the dip angle of the downgoing plate, but subduction geometry is also influenced by other factors. We conducted a numerical modeling study to understand the effect of sediment thickness and density on the downgoing plate speed and dip. We observe that thick sediments on the downgoing plate lead to a slower subduction and a shallower dip, due to the decrease in slab pull and increase of stress along the contact interface associated to a bigger accretionary wedge. Our findings suggest that the effect of sediments might be not limited to the lubrication of the contact interface, but buoyancy and accretionary wedge size also play a role.

\section{Introduction}

The main parameters controlling subduction kinematics and geometry remain poorly understood. Previous work suggested that plate motion depends on the balance between the negative buoyancy of the subducting lithosphere (e.g., Forsyth \& Uyeda, 1975; Becker \& O'Connell, 2001; Conrad \& Lithgow-Bertelloni, 2002) and lithospheric bending, mantle resistance, and shear coupling along the subduction interface (e.g., Conrad \& Hager, 1999; Buffett \& Rowley, 2006). For moderately strong slabs, the plate interface matters (Conrad \& Hager, 1999) and interface rheology has been suggested to control plate speeds (Behr \& Becker, 2018). Sediments entering the trench can influence the stress state of the megathrust (e.g., Lamb, 2006). Due to their low friction and/or high fluid pressure (e.g., Saffer \& Marone, 2003; Saffer \& Tobin, 2011; Bangs et al., 2009; Lamb \& Davis, 2003; Lamb, 2006), sediments might lubricate the plate interface. Hence, their presence is expected to speed up plate motion, all else being equal. For example, Lamb and Davis (2003) suggested that a decrease of the interface shear stresses in the frictional regime due to thick trench sediments might result in the acceleration of convergence rate. Behr and Becker (2018) showed that sediment-lubricated slabs subduct faster than slabs with predominantly mafic material, due to the lower viscosity of the deep interface when abundant sediments subduct.

Considering global observations, the role of sediments remains unclear. Trench sediment thickness seems to be negatively correlated with convergence velocity (e.g., Clift \& Vannucchi, 2004) or subduction velocity (Duarte et al., 2015). Slow converging sys- 
tems are usually associated with sediment accretion (e.g., Clift \& Vannucchi, 2004). However, this relationship at least partially occurs because the time for sediment accumulation is longer if convergence is slow (e.g., Clift \& Vannucchi, 2004). Furthermore, the other variables that affect subduction plate speeds (e.g., slab strength and length, overriding plate thickness, and asthenospheric viscosity) vary widely among modern subduction zones, making it difficult to isolate the effect of interface rheology. Challenges also lie in understanding how subducted sediments are partitioned along the interface at shallow and deep levels in accretionary versus erosional margins (cf. Clift \& Vannucchi, 2004). Several studies, for example, suggest that even in sediment-starved erosional margins, sediments pile up through underplating deeper along the subduction interface (Menant et al., 2020; Calvert et al., 2011; Tewksbury-Christle et al., 2021; Litchfield et al., 2007; Agard et al., 2009; Delph et al., 2021), which could lead to lubrication despite very low sedimentation rates at the trench.

Previous work also focused on the parameters that control the curvature radius of sinking slabs. It has been suggested that slab dip is influenced by a balance between slab buoyancy and hydrodynamic forces related to the corner flow induced in the viscous mantle by the subducting lithosphere (Stevenson \& Turner, 1977; Tovish et al., 1978). Trench migration, slab strength, overriding plate thickness and motion with respect to the mantle are also thought to affect the curvature radius of the slab (Holt et al., 2015; Capitanio \& Morra, 2012; Lallemand et al., 2005; Funiciello et al., 2008; Bellahsen et al., 2005; Capitanio et al., 2009). Numerical models have also suggested that the subducting plate dip can be influenced by sediment thickness at the trench. As the trench sediment thickness increases, the slab unbends due to the seaward growth of the sedimentary wedge (Brizzi et al., 2020).

Here we investigate the role of sediment thickness and buoyancy on subducting plate velocity and slab radius of curvature. We use $2 \mathrm{D}$ thermomechanical models in which the slab sinks into the mantle under its negative buoyancy after an initial push. Rather than sediment lubrication, our setup allows us to isolate the effects of sediment buoyancy. We test how the amount of sediments with different densities influences slab pull and shear stress at the subduction interface, and we compare these outcomes with slab velocity and curvature radius.

\section{Numerical Methods, Model Setup and Model Metrics}

We use the 2D Seismo-Thermo-Mechanical version (van Dinther et al., 2013) of the geodynamic code I2ELVIS (Gerya \& Yuen, 2007). This solves for the conservation of mass, momentum, and energy using a finite difference scheme on a fully staggered Eulerian grid in combination with Lagrangian markers. Except for the asthenospheric mantle that is Newtonian for simplicity, we employ non-Newtonian visco-elasto-plastic rheologies (Gerya \& Yuen, 2007). The effective viscosity is calculated from experimentally constrained dislocation creep flow laws (Table S1). Incoming plate and accretionary wedge sediments, as well as the upper oceanic crust are modeled using a wet quartzite flow law, while the lower oceanic crust is treated as plagioclase. Differences in the frictional behavior of sediments and oceanic lithosphere are mainly related to the i) static friction coefficient $\left(\mu_{s}\right.$ $=0.35$ and 0.5 for sediments and oceanic lithosphere, respectively) and ii) pore fluid pressure factor $(\lambda=0.95$ and 0.4 for sediments and oceanic lithosphere, respectively).

We adapt the model setup of Brizzi et al. (2020), which consists of a 40 Myr old oceanic lithosphere subducting beneath continental lithosphere (Figure 1). The oceanic lithosphere includes a sedimentary layer of variable thickness $d_{\text {sed }}$. A sedimentary wedge is present at the leading edge of the overriding plate. A $12.5 \mathrm{~km}$ thick layer of sticky air mimics the effect of a free surface (e.g., Crameri et al., 2012). Free slip boundary conditions are applied at the top and side boundaries of the model, and we impose a closed boundary condition at the bottom boundary. 

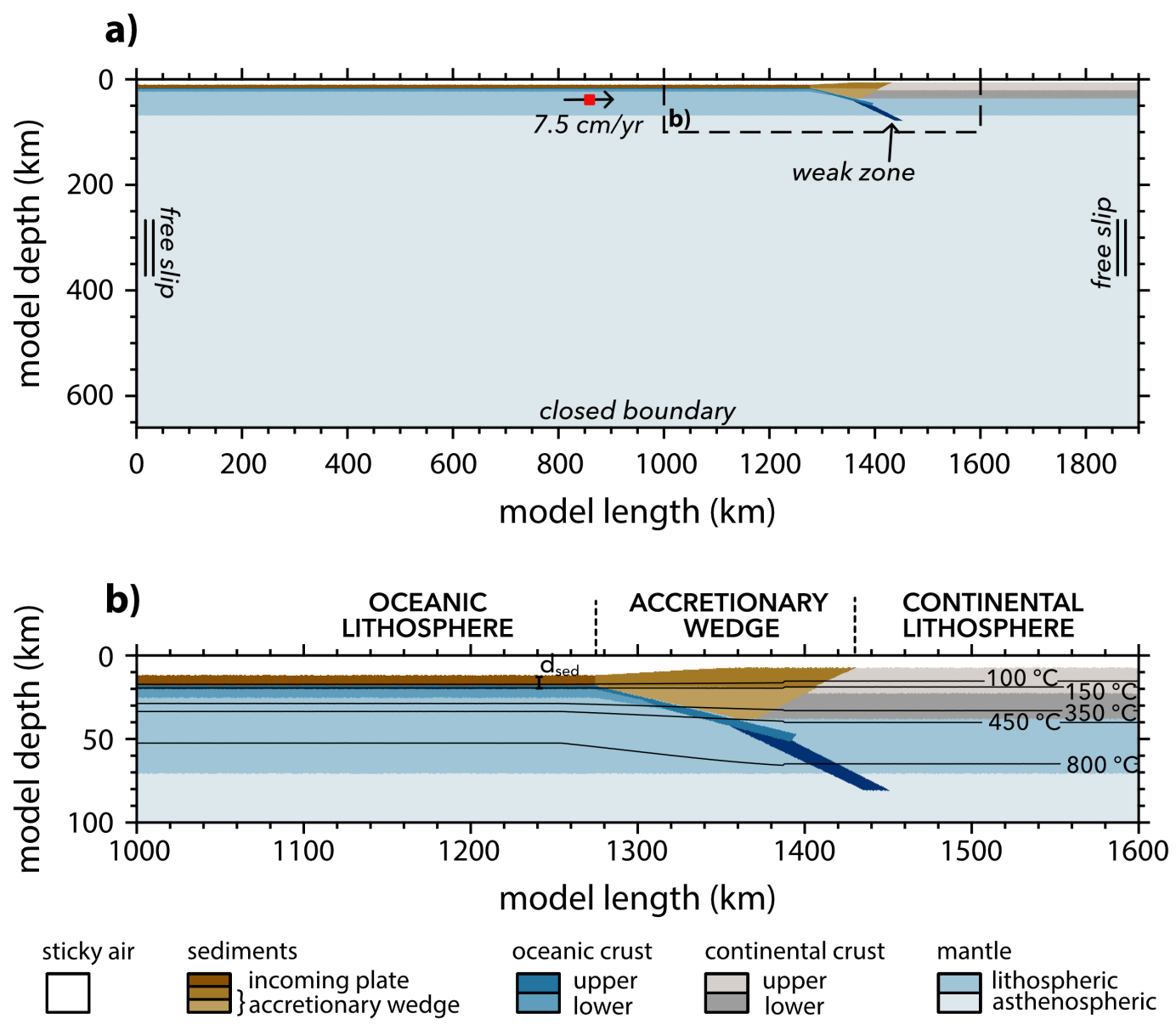

Figure 1. a) Model setup. Subduction proceeds along a weak zone by imposing a fixed velocity (black arrow) on a small region (red rectangle) of the subducting plate until $300 \mathrm{~km}$ of oceanic lithosphere has subducted. The dashed black rectangle marks the high resolution area of the models. b) Zoom of the high resolution area. Black solid lines show the initial temperature field. $d_{\text {sed }}$ is the thickness of incoming plate sediments (set to $6 \mathrm{~km}$ in this model). 
Subduction initiates along a $15^{\circ}$-dipping weak zone (low plastic strength). We impose a constant velocity of $7.5 \mathrm{~cm} / \mathrm{yr}$ until $300 \mathrm{~km}$ of the slab is subducted. After this kinematically prescribed phase, the pushing velocity is removed and subduction is selfdriven. An extended description of the numerical methodology and model setup is given in the supporting information.

For each model, we measure the area of subducted sediments $d_{s s}$, slab velocity $v_{s p}$ during the free sinking phase, radius of curvature $R_{c}$, slab pull $F_{s p}$ and integrated shear stress along the megathrust $F_{s l} . d_{s s}$ is defined as the area of sediments below the continental Moho (Fig. S1b). $v_{s p}$ is defined as the average velocity of the subducting plate during the the free sinking phase, i.e., from $\sim 4 \mathrm{Myr}$ until the slab reaches the $660 \mathrm{~km}$ discontinuity (Fig. S2a). $R_{c}$ is estimated by fitting a circle to the subducting plate center line. $F_{s p}$ (force per length) is defined as $F_{s p}=\Delta \rho g A$, where $\Delta \rho$ is the density contrast between the asthenospheric mantle and the slab, $g$ is the gravitational acceleration, and $A$ is the slab area (Fig. S3). We compute $F_{s p}$ at the beginning of self-consistent subduction ( $4 \mathrm{Myr})$ to ensure that an equal length of slab has subducted in each model. Lastly, $F_{s l}$ is quantified from the length-integrated second invariant of the deviatoric stress tensor in a $3 \mathrm{~km}$-thick region that extends from the trench to the brittle-ductile transition $\left(\sim 450{ }^{\circ} \mathrm{C}\right.$ isotherm; Fig. S4). To be able to compare with slab pull estimates, $d_{s s}$, $R_{c}$, and $F_{s l}$ are also measured at $\sim 4 \mathrm{Myr}$.

\section{Results}

We investigate how sediments influence subduction by varying their a) thickness $d_{\text {sed }}$ from 0 to $6 \mathrm{~km}$ and b) density $\rho_{\text {sed }}$ from 2200 to $2800 \mathrm{~kg} / \mathrm{m}^{3}$. Note that we vary the density of both incoming plate and accretionary wedge sediments. In the following, we first present the evolution of the models with no $\left(d_{\text {sed }}=0 \mathrm{~km}\right)$ and a thick $\left(d_{\text {sed }}=\right.$ $6 \mathrm{~km}$ ) sediment layer on the incoming plate and a reference $\rho_{\text {sed }}$ of $2800 \mathrm{~kg} / \mathrm{m}^{3}$. Then, we address the evolution of the model with thick light sediments $\left(\rho_{\text {sed }}=2200 \mathrm{~kg} / \mathrm{m}^{3}\right)$. Lastly, we focus on the effect of sediments on slab velocity and curvature radius.

\subsection{Model evolution}

\subsubsection{No sediment layer}

During the initial phase of forced subduction, sediments are eroded from the preexisting accretionary wedge and transported along the interface up to a maximum depth of $\sim 80 \mathrm{~km}$ within a thin subduction channel (Fig. 2a-i). When we stop pushing the subducting plate, the slab dip increases (Fig. 2a-ii). Sediments are still eroded from the accretionary wedge and transported to a maximum depth of $\sim 100 \mathrm{~km}$ along the megathrust (Fig. 2a-ii). During this stage, slab velocity increases (Fig. S2a) due to both an increase of slab pull and a decrease of the integrated shear resistance at the base of lithospheric mantle. With ongoing subduction, the slab steepens and becomes almost vertical. When it approaches the $660 \mathrm{~km}$ discontinuity (i.e., bottom model boundary), the slab tip is slightly overturned. This promotes a backward reclined configuration with progressing subduction (Fig. 2a-iii). Sediments subducted below the forearc mantle wedge (depth $>100 \mathrm{~km}$ ) start detaching and exhuming below the continental lithosphere.

\subsubsection{Thick sediment layer}

During the kinematically prescribed subduction, sediments are partially subducted along the megathrust and partially accreted. Accretion occurs both by off-scraping at the front of the wedge and underplating at the rear. The maximum depth reached by subducted sediments is lower compared to the no sediment model (Fig. 2b-i), as underplating promotes the development of an antiformal stack within a thick subduction channel. The dip angle of the slab is lower compared to the no sediment model (Fig. 2b-i). 


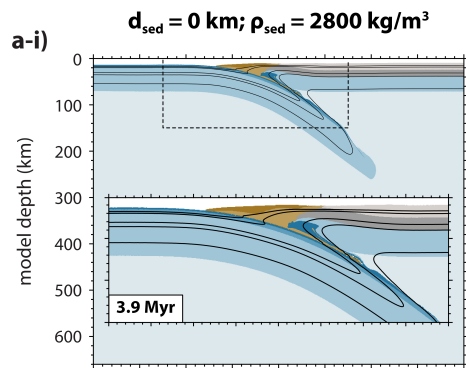

b-i)

$d_{\text {sed }}=6 \mathrm{~km} ; \rho_{\text {sed }}=2800 \mathrm{~kg} / \mathrm{m}^{3}$

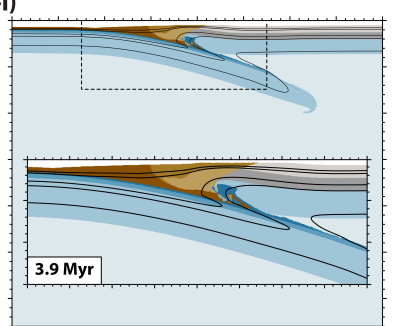

b-ii)

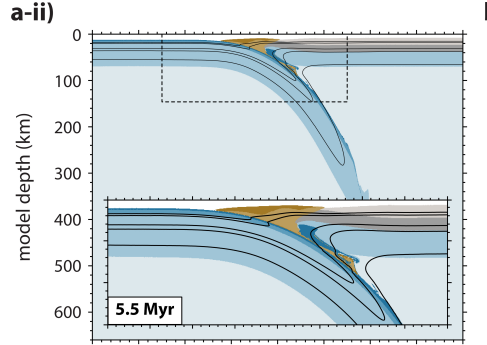

a-iii)

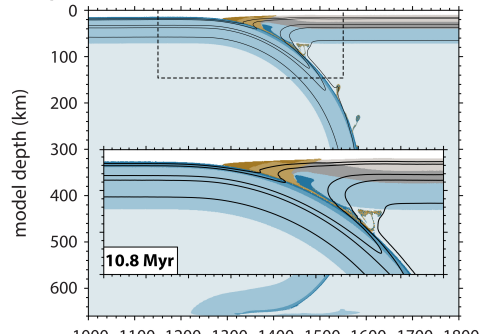

1000110012001300140015001600

model length $(\mathrm{km})$

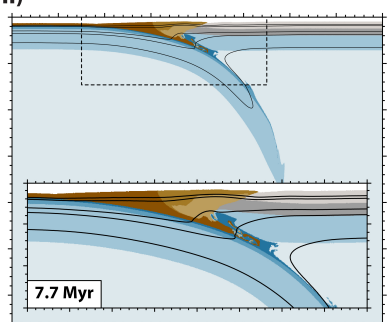

b-iii)

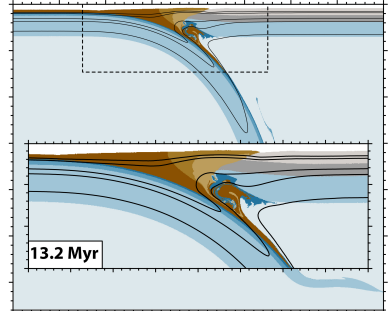

model length $(\mathrm{km})$

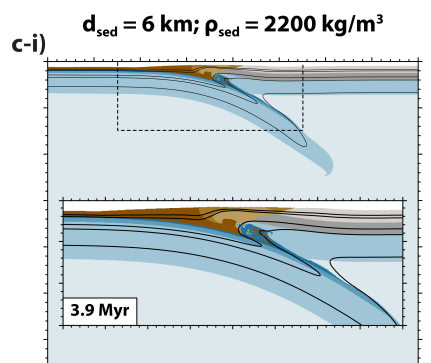

c-ii)

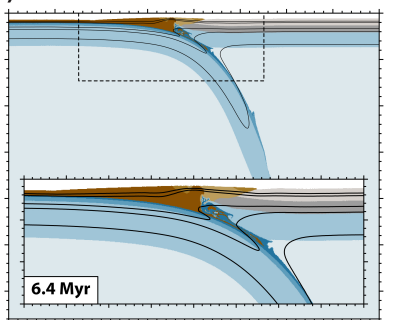

c-iii)

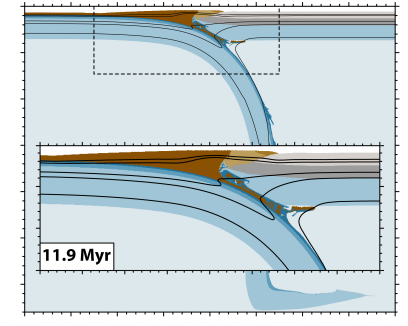

100011001200130014001500160017001800 model length $(\mathrm{km})$

Figure 2. Compositional map of the model with a) thin sediments $\left(d_{\text {sed }}=0 \mathrm{~km} ; \rho_{\text {sed }}=\right.$ $\left.\left.2800 \mathrm{~kg} / \mathrm{m}^{3}\right), \mathrm{b}\right)$ thick sediments $\left(d_{\text {sed }}=6 \mathrm{~km} ; \rho_{\text {sed }}=2800 \mathrm{~kg} / \mathrm{m}^{3}\right)$, and c) thick light sediments $\left(d_{\text {sed }}=6 \mathrm{~km} ; \rho_{\text {sed }}=2200 \mathrm{~kg} / \mathrm{m}^{3}\right)$ roughly at the end of the kinematically constrained subduction (i), free slab sinking (ii) and interaction with the $660 \mathrm{~km}$ discontinuity (iii). Black lines correspond to $100{ }^{\circ} \mathrm{C}, 150{ }^{\circ} \mathrm{C}, 350{ }^{\circ} \mathrm{C}, 450{ }^{\circ} \mathrm{C}$ and $800{ }^{\circ} \mathrm{C}$ isotherms. Color legend for rock types in Figure 1. 
As the pushing velocity is removed, sediments keep piling up onto the base of the accretionary wedge, while a small amount is subducted below the continental Moho (Fig. 2bii). Subduction maintains a shallower dip compared to the no sediment case (Fig. 2bii). During this phase, slab velocity increases but to a lower rate compared to the no sediment case (Fig. S2a). As the slab approaches the $660 \mathrm{~km}$ discontinuity, the dip angle increases. This change in the slab dip promotes an increase of the subduction channel width, such that a larger amount of sediments can be dragged to greater depths and underplate onto the base of the accretionary wedge (Fig. 2b-iii). During sinking, the slab stretches and eventually drapes over the $660 \mathrm{~km}$ discontinuity (Fig. 2b-iii).

\subsubsection{Thick light sediments}

During the initial phase of forced subduction, a low sediment density favors more sediment accretion than subduction. Therefore, at the end of the forced subduction, the amount of sediments below the forearc Moho is lower compared to the reference model. This is because the lower density inhibits sediment descent into the subduction channel (Fig. 2c-i). At this stage, the slab dip is slightly higher than the respective reference model (Fig. 2c-i). As the slab sinks freely into the mantle, the amount of sediments accreted to the wedge increases, while the amount of subducted sediments decreases (Fig. 2cii). During this stage, the slab dip increases. As observed for the respective reference model, this increase in slab dip induces an increase of the subduction channel width, hence an increase of the amount of subducted sediments. However, with ongoing subduction, these sediments tend to be transported upward to the opening of the channel (Fig. 2c-iii). Slab velocity increases as well, but to a higher rate compared to the respective reference model (Fig. S2a). As the slab approaches the $660 \mathrm{~km}$ discontinuity and drapes over it, significant underplating below the continental lithosphere occurs and a sub-horizontal sedimentary plume develops (Fig. 2c-iii).

\subsection{Sediment control on slab velocity}

Our results show that the amount of subducted sediments depends on their initial thickness and density (Fig. 3a). An increase of sediment thickness results in an increase of subducted sediments. For example, for a sediment density of $2800 \mathrm{~kg} / \mathrm{m}^{3}, d_{s s}$ increases by a factor of $\sim 2$ when $d_{\text {sed }}$ is increased from $0 \mathrm{~km}$ to $6 \mathrm{~km}$. For a constant sediment thickness, decreasing sediment density results in a decrease of the amount of material subducted, as a relatively higher sediment buoyancy inhibits subduction. For example, if $d_{\text {sed }}=0 \mathrm{~km}, d_{\text {ss }}$ decreases by a factor of $\sim 3$, if $\rho_{\text {sed }}$ decreases from $2800 \mathrm{~kg} / \mathrm{m}^{3}$ to $2200 \mathrm{~kg} / \mathrm{m}^{3}$. This decrease is higher (factor of $\sim 5.4$ ) if $d_{\text {sed }}=6 \mathrm{~km}$.

The amount of subducted sediments influences slab pull $F_{s p}$ (Fig. 3b). As the sediment thickness increases and more sediments are subducted, $F_{s p}$ decreases by a factor of $\sim 1.2$ and $\sim 2.7$ for $\rho_{\text {sed }}$ of $2800 \mathrm{~kg} / \mathrm{m}^{3}$ and $2200 \mathrm{~kg} / \mathrm{m}^{3}$, respectively. As we decrease $\rho_{\text {sed }}$ and the amount of subducted sediments decreases, $F_{s p}$ increases by a factor of $\sim 1.6$ and $\sim 3.6$, if $d_{\text {sed }}$ is 0 and $6 \mathrm{~km}$, respectively.

Subducting plate velocity $v_{s p}$ is positively correlated to slab pull (Fig. 3c). For $\rho_{\text {sed }}$ $=2800 \mathrm{~kg} / \mathrm{m}^{3}$, the decrease in slab pull that results from the increase in sediment thickness causes a decrease in $v_{s p}$ from $8.8 \mathrm{~cm} / \mathrm{yr}$ to $3.8 \mathrm{~cm} / \mathrm{yr}$. On the other hand, as slab pull increases due to a decrease of sediment density, $v_{s p}$ increases. For example, the increase in slab pull observed when $d_{\text {sed }}=6 \mathrm{~km}$ and $\rho_{\text {sed }}$ decreases from $2800 \mathrm{~kg} / \mathrm{m}^{3}$ to $2200 \mathrm{~kg} / \mathrm{m}^{3}$ results in an increase of $v_{s p}$ from $3.8 \mathrm{~cm} / \mathrm{yr}$ to $5.9 \mathrm{~cm} / \mathrm{yr}$.

We test how the initial kinematically imposed subduction affects slab velocity by pushing the subducting plate at lower rates. We find that a lower pushing velocity results in a slower slab only in the case of thick sediments (Fig. S2b) due to an increase 
a)
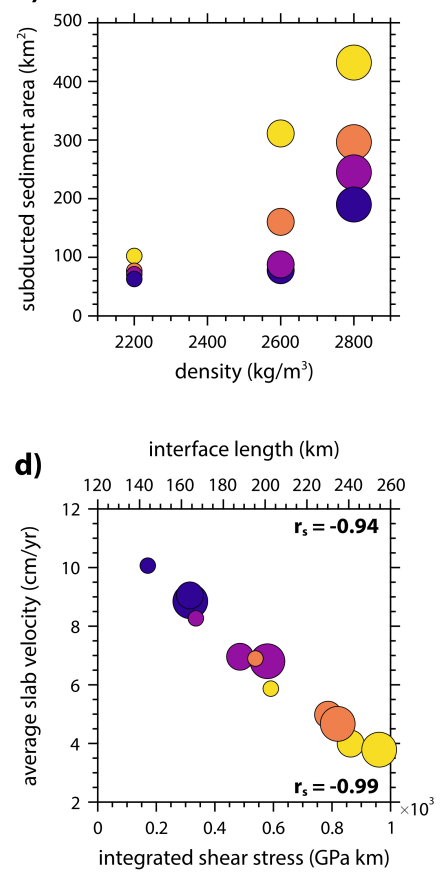

b)

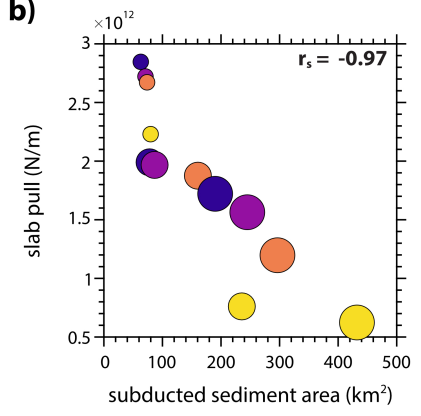

e)

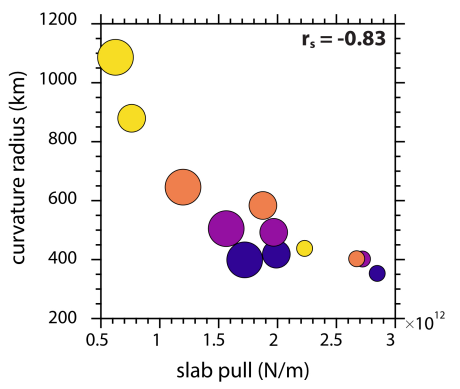

c)

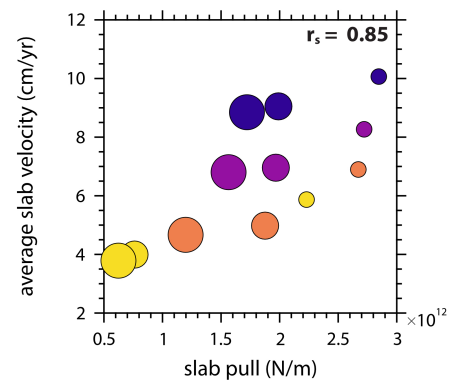

f)

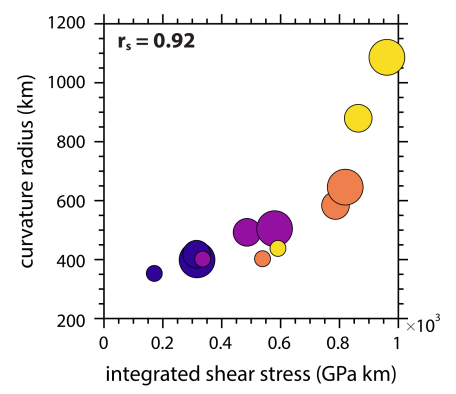

sediment density $\left(\mathrm{kg} / \mathrm{m}^{3}\right)$

$0 \bigcirc \bigcirc$

sediment thickness $(\mathrm{km})$

Figure 3. a) Relationship between sediment thickness, sediment density and amount of sediments subducted below the forearc Moho; b) slab pull as a function of the amount of subducted sediments; c) slab velocity as a function of slab pull; d) slab velocity as a function of megathrust integrated shear stresses and interface length; e) radius of curvature the slab as a function of slab pull; f) curvature radius of the slab as a function of megathrust integrated shear stresses. $r_{s}$ is Spearman's rank correlation coefficient. In panel d) the top and bottom $r_{s}$ values refer to the relationship between average slab velocity and interface length, and average slab velocity and integrated shear stress, respectively. p-values of all relationships is $<0.05$. 
in interface viscosity, as we remove the push and the strain rate decreases. Nonetheless, thick trench sediments result in a slower subducting plate.

Our results also show that increasing the sediment thickness produces an increase of the integrated megathrust shear stress $F_{s l}$ by a factor of $\sim 2$ and $\sim 2.2$, if $\rho_{\text {sed }}$ is 2200 $\mathrm{kg} / \mathrm{m}^{3}$ and $2800 \mathrm{~kg} / \mathrm{m}^{3}$, respectively (Fig. 3d). This increase is mainly due to the development of a wider accretionary wedge that increases the interface downdip length (Fig. 3d). As $F_{s l}$ increases, $v_{s p}$ decreases (Fig. 3d). As opposed to the effect of $d_{s e d}$, a decrease in density promotes a decrease of $F_{s l}$ by a factor of $\sim 1.4-1.5$, hence an increase of $v_{s p}$ (Fig. 3d).

\subsection{Sediment control on slab curvature radius}

Our results show that sediment thickness and density also influence the curvature radius of the slab $R_{c}$. We find that there is a positive relationship between slab pull and $R_{c}$. As $F_{s p}$ decreases with increasing $d_{\text {sed }}$ (Fig. $3 \mathrm{~b}$ ) and the slab gets more buoyant, subduction attains a flatter geometry and the curvature radius increases by a factor of $\sim 1.2$ and $\sim 2.7$, if $\rho_{\text {sed }}$ is $2800 \mathrm{~kg} / \mathrm{m}^{3}$ to $2200 \mathrm{~kg} / \mathrm{m}^{3}$, respectively (Fig. 3e). Conversely, when $F_{s p}$ is higher due to lighter sediments, $R_{c}$ is $\sim 1.1-2.7 \times$ lower (Fig. 3e) and we observe a steeper dip angle.

We also observe a positive correlation between the slab curvature radius and the megathrust shear stress. As $F_{s l}$ increases due to an increase in $d_{s e d}, R_{c}$ increases (Fig. 3f). As $F_{s l}$ decreases due to a lower $\rho_{s e d}, R_{c}$ decreases (Fig. 3f).

\section{Discussion}

\subsection{Sediments and slab velocity}

Sediment subduction is thought to impact plate motion at convergent margins (e.g., Lamb \& Davis, 2003; Behr \& Becker, 2018). This hypothesis relies upon the notion that subducted sediments influence the shear strength of the megathrust (e.g., Lamb \& Davis, 2003; Lamb, 2006). Given their weakening and/or lubricating effect on the plate interface (e.g., Saffer \& Marone, 2003; Saffer \& Tobin, 2011), subducted sediments are thought to favor higher plate speed (e.g., Lamb \& Davis, 2003; Behr \& Becker, 2018) .

Our results show that slab velocity is indeed affected by interface stress and that a negative correlation between slab velocity and integrated megathrust shear stress exists (Fig. 3d), as expected from force balance (Conrad \& Hager, 1999). However, we show that as the incoming sediment thickness and density increase, the integrated shear stress along the megathrust increases as well (Fig. 3d). Given that shear stress averaged over the megathrust does not vary significantly as a function of sediment thickness and density (Fig. S5a), this increase is mainly related to an increase of the interface length (Fig. 3d, Fig. S5b) due to the presence of a wider accretionary wedge that thickens the upper plate. The larger interface length promotes an increase of the total resistance to subduction, which eventually slows down the slab (Fig. 3d).

Subducted sediments decrease plate speed also by decreasing slab pull due to their positive buoyancy. We find that increasing the incoming plate sediment thickness favors the formation of a thick subduction channel, and a large amount of sediments can be subducted (Fig. 3a) resulting in a reduction of slab pull (Fig. 3b) and, in turn, lower subduction velocity (Fig. 3c). Keum and So (2021) showed that sediment buoyancy affects trench motion, with thick trench sediments resulting in a slower trench retreat. This relationship between amount of subducted sediments, slab pull and velocity is also supported by the outcomes of models with different sediment density. Low sediment density makes sediment subduction more difficult, so that slab pull is higher if sediments 
are relatively light (Fig. 3b). This causes higher slab velocities for such lower sediment densities (Fig. 3c).

We suggest that the role of sediments in subduction dynamics is not limited to the lubrication or rheology of the plate interface alone (Behr \& Becker, 2018), but that they also play an important role in modulating the length of the interface through the construction of an accretionary wedge. Subducted sediments also induce variations in the density structure and buoyancy of the subducting lithosphere, which can further affect plate motion.

\subsection{Sediments and slab curvature radius}

Our results show that larger integrated megathrust shear stresses result in a larger slab curvature radius (Fig. 3f) due to the development of a wide accretionary wedge that increases the interface downdip width. This is in agreement with previous studies suggesting that accretion of sediments can load and unbend the slab, reducing the angle of subduction (Karig \& Sharman, 1975; Seely et al., 1974; Jacob et al., 1977; Cross \& Pilger, 1982; Brizzi et al., 2020). Similarly, thick overriding plates have been shown to increase the curvature radius of the slab (Holt et al., 2015; Capitanio et al., 2011).

We also find that there is a negative relationship between slab pull and slab curvature radius (Fig. 3e). With increasing subducted sediments, slab pull decreases (Fig. 3b) and subduction attains a shallower dipping geometry. Slab dip is expected to be influenced by slab pull (e.g., Vlaar \& Wortel, 1976; Molnar \& Atwater, 1978; Uyeda \& Kanamori, 1979). However, analog experiments show that a larger slab pull promotes slab rollback and shallowing (Funiciello et al., 2008; Martinod et al., 2005). Furthermore, a correlation between subducting plate age and slab dip (Cruciani et al., 2005; Lallemand et al., 2005) or slab pull force (Lallemand et al., 2005) is not found in compilations of natural subduction zone parameters. Our findings confirm that the overriding plate structure can influence subduction geometry, but also suggest that slab pull force might factor in.

\subsection{Sediment accretion vs. subduction}

It is widely recognized that subduction zones can either be accretionary or erosive (e.g., von Huene \& Scholl, 1991), but the mechanisms by which sediments are subducted/eroded or accreted are still debated. Our results confirm previous suggestions that the amount of trench sediments influences whether accretion or erosion occurs (Fig. 4) (e.g., von Huene \& Scholl, 1991; Clift \& Vannucchi, 2004; Cloos \& Shreve, 1988). In our models, the lack of incoming plate sediments results in the erosion and subsequent subduction of the protowedge sediments (Fig. 4a). As the sediment thickness increases, sediments are mostly accreted to the front of the proto-wedge (Fig. 4b-d), but sediment subduction simultaneously also occurs. Rheological properties are also expected to influence the behavior of subducted sediments. Currie et al. (2007) showed that for sediments with wet quartzite rheology, sediment density exerts the primary control on whether sediment subduction can occur. As sediment viscosity increases, entrainment by the subducting plate tends to dominate and sediments are more easily subducted to mantle depths (Currie et al., 2007).

Convergent margins with high sediment supply are also commonly considered loci of sediment accretion (e.g., Clift \& Vannucchi, 2004; Cloos \& Shreve, 1988), but transitions to an erosional regime have been documented in Costa Rica, northern Apennines and southern Alaska (Amato \& Pavlis, 2010; Vannucchi et al., 2004, 2008). The triggers for switching from one tectonic regime to another remain poorly known. Our models show that the increase in slab dip during the free subduction phase allows for the widening of the subduction channel, such that the amount of subducted sediments increases through time (Fig. 4c-d). Due to the increase of the subduction channel capacity, the accretionary 
a)

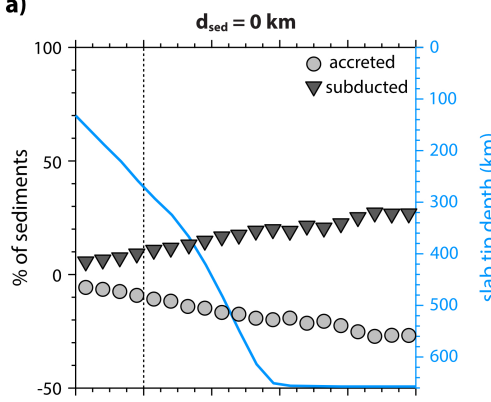

c)

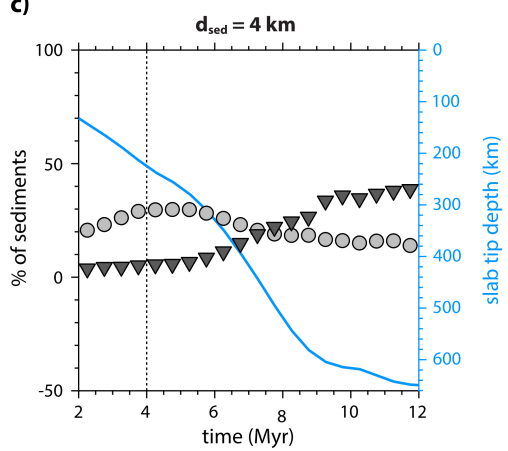

b)

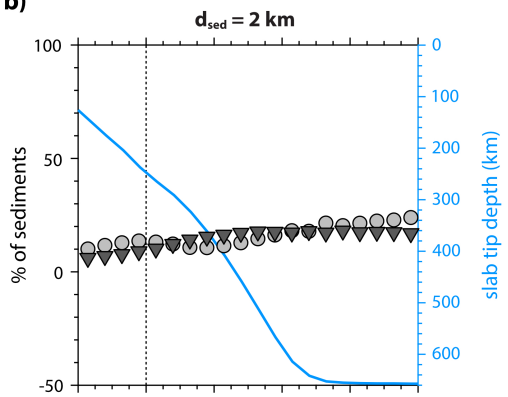

d)

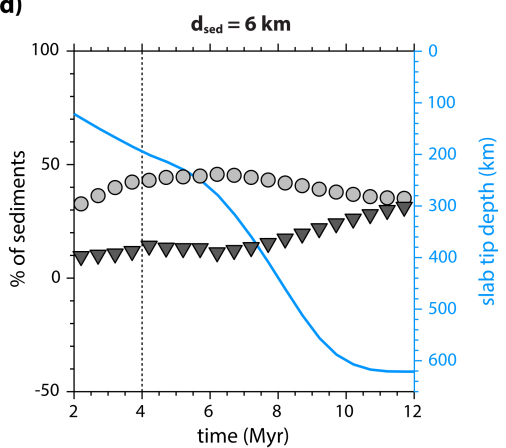

Figure 4. Percentage of accreted and subducted sediments, and slab tip depth as a function of time for a) $d_{\text {sed }}=0 \mathrm{~km}$ and, b) $d_{\text {sed }}=2 \mathrm{~km}$, c) $d_{\text {sed }}=4 \mathrm{~km}$, and d) $d_{\text {sed }}=6 \mathrm{~km}$. Sediment density $\rho_{\text {sed }}$ is $2800 \mathrm{~kg} / \mathrm{m}^{3}$. Note that the percentage of accreted sediments in panel a) is negative due to the decrease in size of the proto-wedge as sediments are eroded. The dashed black line marks the timing of push removal. Details on how the percentage of accreted and subducted sediments are estimated are given in the supplementary material.

wedge dynamically readjusts after attaining steady state conditions (e.g., Willett \& Brandon, 2002), such that the amount of accreted sediments decreases to accommodate the increase in sediment subduction (Fig. 4c-d). Thus, the partition of the incoming plate sediments in accreted or subducted is a time-dependent feature, which seems to be strongly influenced by the slab dip (Cloos \& Shreve, 1988). Hence, the common view of accretionary or erosive convergent margins seems to be overly simplified (e.g., Simpson, 2010), as sediment subduction and accretion are interlinked processes.

\subsection{Modeling limitations}

Our initial geometry includes a pre-existing accretionary wedge that has been shown to influence both slab velocity and radius of curvature by influencing the integrated megathrust shear stress. The constant sediment flux to the trench in our models does not fully capture variations in sediment thickness in nature. Our slab pull estimates are low compared to the typical values of $10^{13} \mathrm{~N} / \mathrm{m}$ (e.g., Turcotte \& Schubert, 2002), as we derive them at the initial stage of subduction. This suggests that for a young (40 Myr old) plate, sediment buoyancy has a pronounced effect, but we caution that this effect might be lower for older, thicker lithosphere. Eclogitization of the mafic components is expected to contribute to slab pull and influence the force balance, as well the integrated shear stress (Behr \& Becker, 2018). Additional aspects that we neglect are fluid transport and compaction effects, as well metasomatic alteration of subducting sediments (Saffer \& Tobin, 2011). Erosion and sedimentation are not included in our models, but we might expect these processes to influence both slab velocity and curvature radius by affecting the sed- 
iment supply to the trench. Our simulations are 2D, and so we neglect along-strike variations of subducted sediments, which are shown to be important for along-strike variations of trench velocity and curvature (Keum \& So, 2021). Despite such simplifications, our numerical models allow us to identify important effects of sediment thickness and buoyancy on slab dynamics and to better understand long-term behavior of convergent margins.

\section{Conclusions}

Sediment subduction can affect the interface geometry and effective slab pull, hence slab morphology and subducting plate speed. Thick sediments promote thickening of the overriding plate through the development of a wide accretionary wedge that increases the downdip length of the plate interface, hence resistance to subduction. Thick sediments can also slow down the subducting plate by partly offsetting the negative buoyancy of the slab. The larger integrated interface shear stress and slab buoyancy due to thick sediments promote a larger curvature radius of the slab. Accretionary margins can experience periods of erosion due to changes in the slab dip that can result in oscillations of subduction rate and megathrust stress over time. We suggest that the effect of sediments on subduction dynamics is not straightforward. Future studies should address not only the capacity of sediments to lubricate and/or weaken the plate interface, but also how their presence affect wedge and subduction dynamics.

\section{Acknowledgments}

TWB was partially supported by EAR-1925939 and EAR-1853856. WMB was partially supported by European Research Council (ERC) Starting Grant S-SIM (947659). IvZ was funded by the Royal Society (UK) through Research Fellows Enhancement Award RGF $\backslash \mathrm{EA} \backslash 181084$. LDZ was supported by the Swiss National Science Foundation (SNSF) (grant P400P2_199295). We thank A. Pusok and F. Funiciello for constructive comments. Model executables, input and output files for the model with $d_{\text {sed }}=0 \mathrm{~km}$ and $d_{\text {sed }}=$ $6 \mathrm{~km}$ will be archived on Zenodo and will be publicly available. For the purpose of peer review, a copy of the content of the repository is temporarily available at https://utexas.box.com/s/18sw339q42frz6k9bte4xqsuzjuaeq92.

\section{References}

Agard, P., Yamato, P., Jolivet, L., \& Burov, E. (2009). Exhumation of oceanic blueschists and eclogites in subduction zones: timing and mechanisms. EarthScience Reviews, 92(1-2), 53-79.

Amato, J. M., \& Pavlis, T. L. (2010). Detrital zircon ages from the Chugach terrane, southern Alaska, reveal multiple episodes of accretion and erosion in a subduction complex. Geology, 38(5), 459-462.

Bangs, N. L., Moore, G. F., Gulick, S. P., Pangborn, E. M., Tobin, H. J., Kuramoto, S., \& Taira, A. (2009). Broad, weak regions of the Nankai Megathrust and implications for shallow coseismic slip. Earth and Planetary Science Letters, 284(1-2), 44-49. doi: 10.1016/j.epsl.2009.04.026

Becker, T. W., \& O'Connell, R. J. (2001). Predicting plate velocities with mantle circulation models. Geochemistry, Geophysics, Geosystems, 2(12). doi: 10 $.1029 / 2001 \mathrm{GC} 000171$

Behr, W. M., \& Becker, T. W. (2018). Sediment control on subduction plate speeds. Earth and Planetary Science Letters, 502, 166-173. doi: 10.1016/j.epsl.2018.08 .057

Bellahsen, N., Faccenna, C., \& Funiciello, F. (2005). Dynamics of subduction and plate motion in laboratory experiments: Insights into the "plate tectonics" behavior of the Earth. Journal of Geophysical Research: Solid Earth, 110(1), 
1-15. doi: 10.1029/2004JB002999

Brizzi, S., van Zelst, I., Funiciello, F., Corbi, F., \& van Dinther, Y. (2020). How Sediment Thickness Influences Subduction Dynamics and Seismicity. Journal of Geophysical Research: Solid Earth, 125(8), 1-19. doi: 10.1029/2019JB018964

Buffett, B. A., \& Rowley, D. B. (2006). Plate bending at subduction zones: Consequences for the direction of plate motions. Earth and Planetary Science Letters, 245(1-2), 359-364. doi: 10.1016/j.epsl.2006.03.011

Calvert, A. J., Preston, L. A., \& Farahbod, A. M. (2011). Sedimentary underplating at the cascadia mantle-wedge corner revealed by seismic imaging. Nature Geoscience, 4 (8), 545-548.

Capitanio, F. A., Faccenna, C., Zlotnik, S., \& Stegman, D. R. (2011). Subduction dynamics and the origin of Andean orogeny and the Bolivian orocline. Nature, 480(7375), 83-86. doi: 10.1038/nature10596

Capitanio, F. A., \& Morra, G. (2012). The bending mechanics in a dynamic subduction system: Constraints from numerical modelling and global compilation analysis. Tectonophysics, 522-523, 224-234. doi: 10.1016/j.tecto.2011.12.003

Capitanio, F. A., Morra, G., \& Goes, S. (2009). Dynamics of plate bending at the trench and slab-plate coupling. Geochemistry, Geophysics, Geosystems, 10(4).

Clift, P., \& Vannucchi, P. (2004). Controls on tectonic accretion versus erosion in subduction zones: Implications for the origin and recycling of the continental crust. Reviews of Geophysics, 42(2). doi: 10.1029/2003RG000127

Cloos, M., \& Shreve, R. L. (1988). Subduction-channel model of prism accretion, melange formation, sediment subduction, and subduction erosion at convergent plate margins: 1. background and description. Pure and Applied Geophysics, $128(3), 455-500$.

Conrad, C. P., \& Hager, B. H. (1999). Effects of plate bending and fault strength at subduction zones on plate dynamics. Journal of Geophysical Research: Solid Earth, 104(B8), 17551-17571. doi: 10.1029/1999jb900149

Conrad, C. P., \& Lithgow-Bertelloni, C. (2002). How mantle slabs drive plate tectonics. Science, 298(5591), 207-209. doi: 10.1126/science.1074161

Crameri, F., Schmeling, H., Golabek, G., Duretz, T., Orendt, R., Buiter, S., ... Tackley, P. (2012). A comparison of numerical surface topography calculations in geodynamic modelling: an evaluation of the 'sticky air'method. Geophysical Journal International, 189(1), 38-54.

Cross, T. A., \& Pilger, R. H. (1982). Controls of subduction geometry location of magmatic arcs and tectonics of arc and back-arc regions. Geological Society of America Bulletin, 93(6), 545-562. doi: 10.1130/0016-7606(1982)93〈545: COSGLO $>2.0 . \mathrm{CO} ; 2$

Cruciani, C., Carminati, E., \& Doglioni, C. (2005). Slab dip vs. lithosphere age: No direct function. Earth and Planetary Science Letters, 238(3-4), 298-310. doi: 10.1016/j.epsl.2005.07.025

Currie, C. A., Beaumont, C., \& Huismans, R. S. (2007). The fate of subducted sediments: A case for backarc intrusion and underplating. Geology, 35(12), 11111114.

Delph, J. R., Thomas, A. M., \& Levander, A. (2021). Subcretionary tectonics: Linking variability in the expression of subduction along the cascadia forearc. Earth and Planetary Science Letters, 556, 116724.

Duarte, J. C., Schellart, W. P., \& Cruden, A. R. (2015). How weak is the subduction zone interface? Geophysical Research Letters, 42(8), 2664-2673. doi: 10 .1002/2014GL062876

Forsyth, D., \& Uyeda, S. (1975). On the Driving Forces of Plate Tectonics. Geophysical Journal of the Royal Astronomical Society, 40(3), 465-474. doi: 10.1111/j .1365-246X.1975.tb04143.x

Funiciello, F., Faccenna, C., Heuret, A., Lallemand, S., Di Giuseppe, E., \& Becker, T. W. (2008). Trench migration, net rotation and slab-mantle 
coupling. $\quad$ Earth and Planetary Science Letters, 271(1-4), 233-240. $\quad$ doi: 10.1016/j.epsl.2008.04.006

Gerya, T. V., \& Yuen, D. A. (2007). Robust characteristics method for modelling multiphase visco-elasto-plastic thermo-mechanical problems. Physics of the Earth and Planetary Interiors, 163(1-4), 83-105. doi: 10.1016/ j.pepi.2007.04.015

Holt, A. F., Buffett, B. A., \& Becker, T. W. (2015). Overriding plate thickness control on subducting plate curvature. Geophysical Research Letters, 42(10), 3802-3810. doi: 10.1002/2015GL063834

Jacob, K. H., Nakamura, K., \& Davies, J. N. (1977). Trench-Volcano Gap Along the Alaska-Aleutian Arc: Facts, and Speculations on the Role of Terrigenous Sediments. American Geophysical Union, 1, 243-258.

Karig, D. E., \& Sharman, G. F. (1975). Subduction and accretion in trenches. Bulletin of the Geological Society of America, 86(3), 377-389. doi: 10.1130/0016 -7606(1975)86<377:SAAIT $>2.0 . \mathrm{CO} ; 2$

Keum, J.-Y., \& So, B.-D. (2021). Effect of buoyant sediment overlying subducting plates on trench geometry: 3d viscoelastic free subduction modeling. Geophysical Research Letters, e2021GL093498.

Lallemand, S., Heuret, A., \& Boutelier, D. (2005). On the relationships between slab dip, back-arc stress, upper plate absolute motion, and crustal nature in subduction zones. Geochemistry, Geophysics, Geosystems, 6(9). doi: 10.1029/2005GC000917

Lamb, S. (2006). Shear stresses on megathrusts: Implications for mountain building behind subduction zones. Journal of Geophysical Research, 111(B7). doi: 10 $.1029 / 2005 j \mathrm{~b} 003916$

Lamb, S., \& Davis, P. (2003). Cenozoic climate change as a possible cause for the rise of the Andes. Nature, 425 (6960), 792-797. doi: 10.1038/nature02049

Litchfield, N., Ellis, S., Berryman, K., \& Nicol, A. (2007). Insights into subductionrelated uplift along the hikurangi margin, new zealand, using numerical modeling. Journal of Geophysical Research: Earth Surface, 112(F2).

Martinod, J., Funiciello, F., Faccenna, C., Labanieh, S., \& Regard, V. (2005). Dynamical effects of subducting ridges: insights from 3-d laboratory models. Geophysical Journal International, 163(3), 1137-1150.

Menant, A., Angiboust, S., Gerya, T., Lacassin, R., Simoes, M., \& Grandin, R. (2020). Transient stripping of subducting slabs controls periodic forearc uplift. Nature communications, 11(1), 1-10.

Molnar, P., \& Atwater, T. (1978). Interarc spreading and Cordilleran tectonics as alternates related to the age of subducted oceanic lithosphere. Earth and Planetary Science Letters, 41, 330-340. doi: 10.1215/-65-1-1

Saffer, D. M., \& Marone, C. (2003). Comparison of smectite- and illite-rich gouge frictional properties: Application to the updip limit of the seismogenic zone along subduction megathrusts. Earth and Planetary Science Letters, 215(1-2), 219-235. doi: 10.1016/S0012-821X(03)00424-2

Saffer, D. M., \& Tobin, H. J. (2011). Hydrogeology and Mechanics of Subduction Zone Forearcs : Fluid Flow and Pore Pressure. Annual Review of Earth and Planetary Sciences, 39, 157-186. doi: 10.1146/annurev-earth-040610-133408

Seely, D., Vail, P., \& Walton, G. (1974). Trench slope model. In The geology of continental margins (pp. 249-260). Springer.

Simpson, G. D. (2010). Formation of accretionary prisms influenced by sediment subduction and supplied by sediments from adjacent continents. Geology, 38(2), 131-134.

Stevenson, D. J., \& Turner, J. S. (1977). Angle of subduction. Nature, 270(5635), 334-336. doi: 10.1038/270334a0

Tewksbury-Christle, C., Behr, W., \& Helper, M. (2021). Tracking deep sediment underplating in a fossil subduction margin: implications for interface rheology 
and mass and volatile recycling. Geochemistry, Geophysics, Geosystems, 22, e2020GC009463.

Tovish, A., Schubert, G., \& Luyendyk, B. P. (1978). Mantle flow pressure and the angle of subduction: Non-Newtonian corner flows. Journal of Geophysical Research: Solid Earth, 83(B12), 5892-5898. doi: 10.1029/jb083ib12p05892

Turcotte, D. L., \& Schubert, G. (2002). Geodynamics. Cambridge university press.

Uyeda, S., \& Kanamori, H. (1979). Back-arc opening and the mode of subduction. Journal of Geophysical Research: Solid Earth, 84(B3), 1049-1061.

van Dinther, Y., Gerya, T. V., Dalguer, L. A., Mai, P. M., Morra, G., \& Giardini, D. (2013, dec). The seismic cycle at subduction thrusts: Insights from seismothermo-mechanical models. Journal of Geophysical Research: Solid Earth, 118(12), 6183-6202. doi: 10.1002/2013JB010380

Vannucchi, P., Galeotti, S., Clift, P. D., Ranero, C. R., \& von Huene, R. Long-term subduction-erosion along the Guatemalan margin of the Middle America Trench. Geology, 32(7), 617-620.

Vannucchi, P., Remitti, F., \& Bettelli, G. (2008). Geological record of fluid flow and seismogenesis along an erosive subducting plate boundary. Nature, 451(7179), 699-703.

Vlaar, N. J., \& Wortel, M. J. (1976). Lithospheric aging, instability and subduction. Tectonophysics, 32(3-4), 331-351. doi: 10.1016/0040-1951(76)90068-8

von Huene, R., \& Scholl, D. W. (1991). Observations at convergent margins concerning sediment subduction, subduction erosion, and the growth of continental crust. Reviews of Geophysics, 29(3), 279-316.

Willett, S. D., \& Brandon, M. T. (2002). On steady states in mountain belts. Geology, 30(2), 175-178. 